\title{
Research on Modeling and Faults Diagnosis of Aero-engine Ignition Sys- tem
}

\author{
Xu Meng*, Yin Yaping and Xia Youbin
}

Aeronautical Automation College, Civil Aviation University of China, Tianjin, China

\begin{abstract}
Aero-engine ignition system, which includes ignition power, ignition exciter, ignition lead and ignition spark plugs, is the core of the engine. The reliability of an ignition system is a key factor whether the engine can run safely and efficiently or not. For improving the safety and continuing airworthiness of the aircraft, it is highly meaningful to do some research on the faults diagnosis of ignition system. This paper mainly focuses on the diagnosis method research and diagnosis system design of aero- engine ignition system faults. In order to cope with this problem, the ignition system mathematical model was designed and with which we can simulate ignition system faults and establish an ignition system theory database. Then experimental system was built to simulate the real ignition system faults to generate ignition system simulation database. Based on the ignition system fault database, the waveform image matching algorithm was used to achieve the real ignition waveform comparison with waveform in faults database. At last, ignition system faults diagnosis system is presented based on diagnostic platform and industrial control computer equipped with high-speed data acquisition card. The analysis result suggests that the ignition system faults diagnosis system can identify typical ignition faults accurately.
\end{abstract}

Keywords: Aero-engine, Ignition system, Mathematical model, Faults diagnosis, Faults database, Waveform image matching.

\section{INTRODUCTION}

All aero-engines are equipped with ignition system which are composed of ignition power, ignition exciter, ignition lead and ignition spark plug. Ignition system and starting system coordinate to work together to make the fuel mixture burn in the combustion chamber for producing engine working conditions when starting the engine on the ground. While in the flight, ignition system works alone.

During the engine start process, there may be starter or ignition faults. With the growth of the aircraft run time, ignition lead, ignition exciter, ignition spark plug and other parts would gradually deteriorate or power loss which could cause the engine ignition unsuccessful. These faults can lower the starting performance of engine on the ground and in the air, and reduce the efficiency of fault diagnosis and extended flight inspection time. For these faults are difficult to be found in parking status, the aero-engine ignition faults even could cause the engine stop and result in flight accidents. The typical faults of aero-engine ignition system are ignition incentive internal partial short circuit, lead abrasion, spark plug coked and the gap between two plates wide or narrow. Ramsay and Nethercot introduced a method to diagnose the engine ignition internal combustion faults. They simply use the primary circuit of the ignition system to obtain a small amount of energy from the spark plug, and a row of fixed ignition image was obtained by a small cathode ray tube screen during the engine running. Each image corresponds to a plug ignition, and images are sequentially displayed on the screen in accordance with the ignition sequence. Therefore, the internal combustion engine ignition faults can be determined by the corresponding position of the image. The shape of the image would change depending on the type of fault occurred [1]. Berkey, Wm. E et al. described a comprehensive engine tester equipped with microcomputer testing station that he instrument determine the aero ignition system faults by comparing the engine ignition system fault ignition waveforms seized by ignition oscilloscope with the standard ignition waveforms [2].

In this paper the ignition system mathematical model which composed of ignition exciter, ignition lead and ignition spark plug was established to analysis the resistance, capacitance and inductance parameter changes under faulty conditions. With the starter ignition experimental system to simulate ignition components faults, acquire ignition waveform and establish ignition system faults database, research on the ignition waveform matching and acceleration algorithms, compared the ignition waveforms with the ignition component faults database waveform data to achieve ignition components faults diagnosis. The ignition system faults diagnosis logic was shown in Fig. (1).

The rest of this paper is organized as follows: Section 1 introduces the ignition mathematical model composed of ignition exciters, ignition leads and ignition spark plug and the faults mathematics database was built. In section 2, ignition experimental system was presented to generate the faults experimental database. In section 3, typical ignition system 


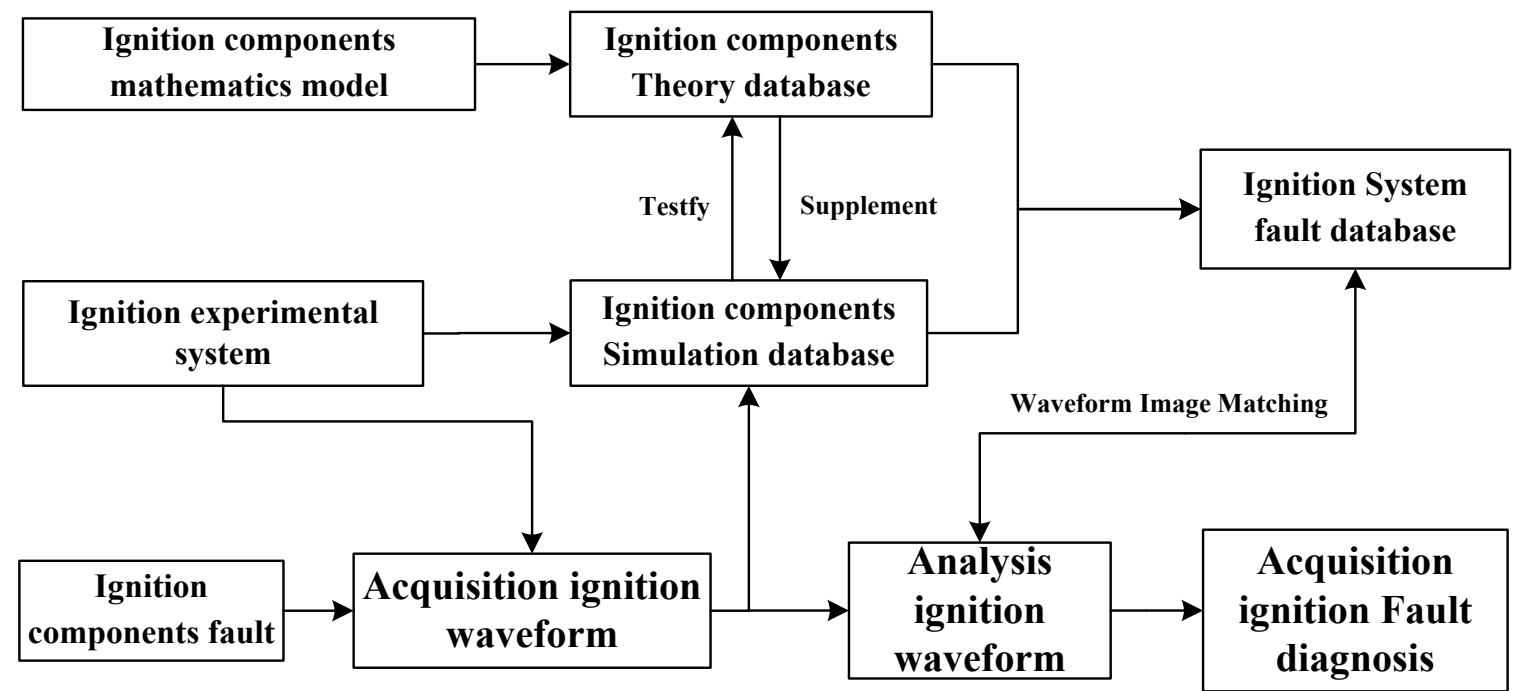

Fig. (1). Ignition system faults diagnosis logic.

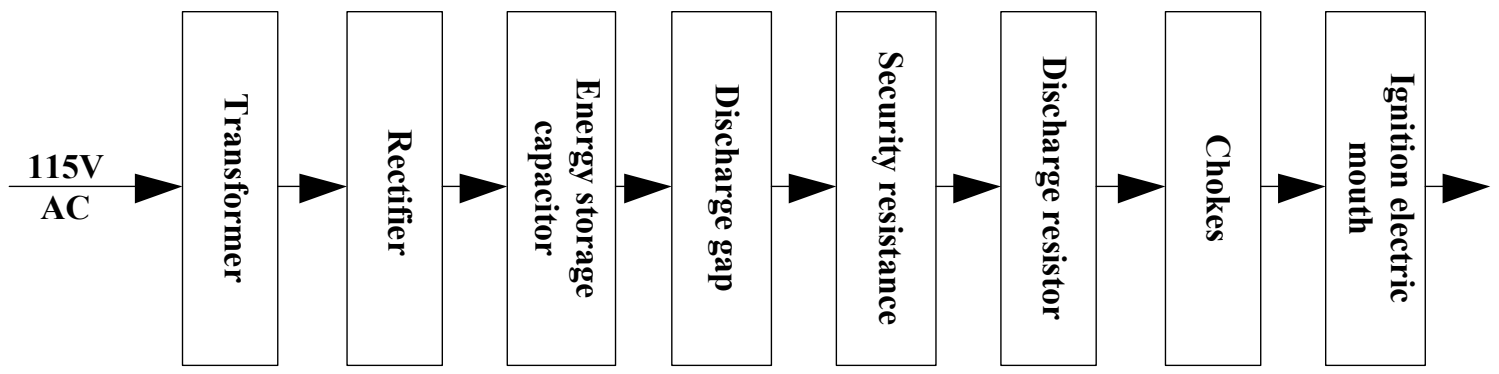

Fig. (2). High-voltage AC ignition system workflow.

faults waveform pretreatment which include the selection characteristic parameters and waveform signal split procedures. In section 4, waveform image matching algorithm was introduced. Ignition system faults and result analysis was shown in section 5. And conclusions are presented in the last part.

\section{IGNITION SYSTEM MATHMATICAL MODEL}

Aero-engine ignition system can be divided into DC ignition device and $\mathrm{AC}$ ignition device. $\mathrm{AC}$ ignition is more commonly used in more electric aero-engine. $\mathrm{AC}$ ignition is powered by $115 \mathrm{~V} / 400 \mathrm{HZ} \mathrm{AC}$ which is composed of transformer, rectifier, energy storage capacitor, discharge gap, chokes, discharge resistor, security resistance and ignition spark plug. The work process of aero-engine ignition system can be described as follows: Firstly, $115 \mathrm{~V} / 400 \mathrm{HZ} \mathrm{AC}$ is supplied to the ignition system. Transformer would generate a high voltage alternating current. Then the high-voltage rectifier would cross the rectifier. Secondly, the energy storage capacitor would charge until the voltage can breakdown the discharge gap. Then the energy storage by energy storage capacitor would pass through chokes and supply power to ignition spark plug. Then sparks would be produced to ignite the mixture gas. The high-voltage AC ignition system workflow is shown in Fig. (2).
High-voltage AC ignition system circuit diagram is shown in Fig. (3), and its equivalent model of the discharge module is shown in Fig. (4). According to the equivalent model of the AC type aviation ignition circuit, the mathematical model of the discharge module is built to analyze the circuit fault.

The mathematical model of the discharge module:

$$
\left\{\begin{array}{l}
i(t)=-C \frac{d u_{C}(t)}{d t} \\
u_{C}(\mathrm{t})=L \frac{d i_{C}(\mathrm{t})}{d t}+\left[\left(r(t)+R_{e q}\right) i(t)\right] \\
r(t)=d / \sqrt{\frac{2 \alpha}{p}} \int_{0}^{\tau} i^{2}(t) d t \\
u_{O}(t)=i(t) r(t)
\end{array}\right.
$$

Where $u_{C}(t)$ is the voltage on the spark plug, $u_{C}(t)$ is the voltage on the storage capacitor, $i(t)$ is the current flowing through the energy storage capacitor, $C$ is the storage capacitor, $L$ is the equivalent inductance of discharge circuit, $R_{e q}$ is the equivalent resistance ignition lead, $r(t)$ is a dynamic resistance of spark plug, $d$ is the length of the air-gap of the spark plug, $\alpha$ is the spark coefficient, $\quad p$ is the pressure. 


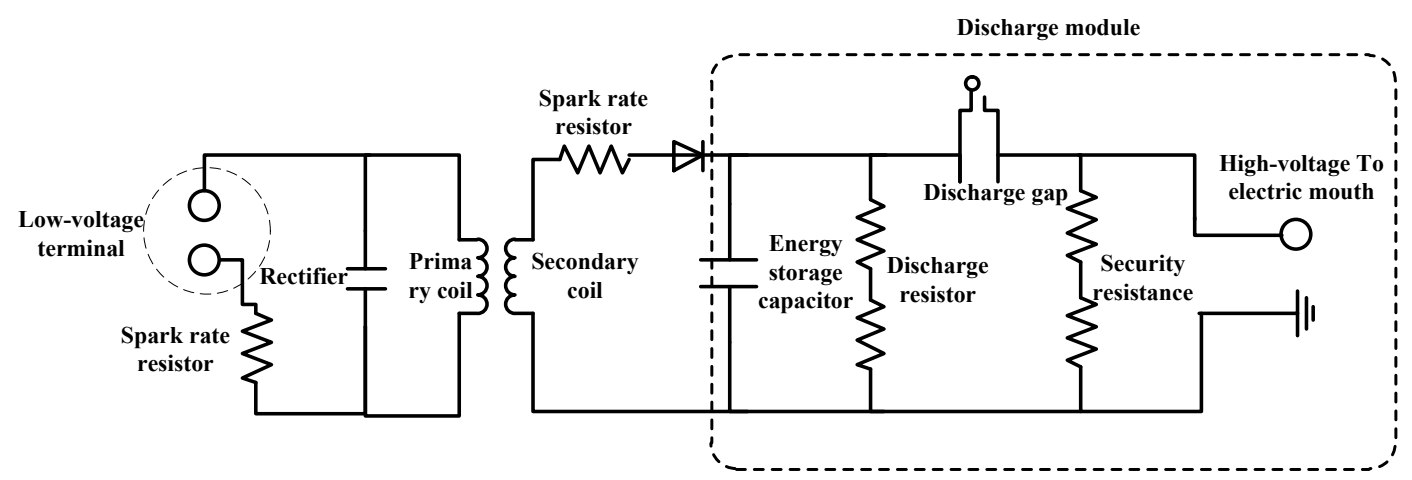

Fig. (3). High-voltage AC ignition system circuit diagram.

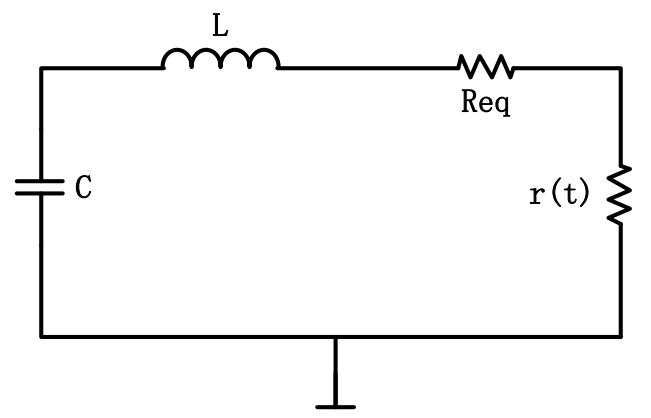

Fig. (4). Equivalent model of the discharge model.
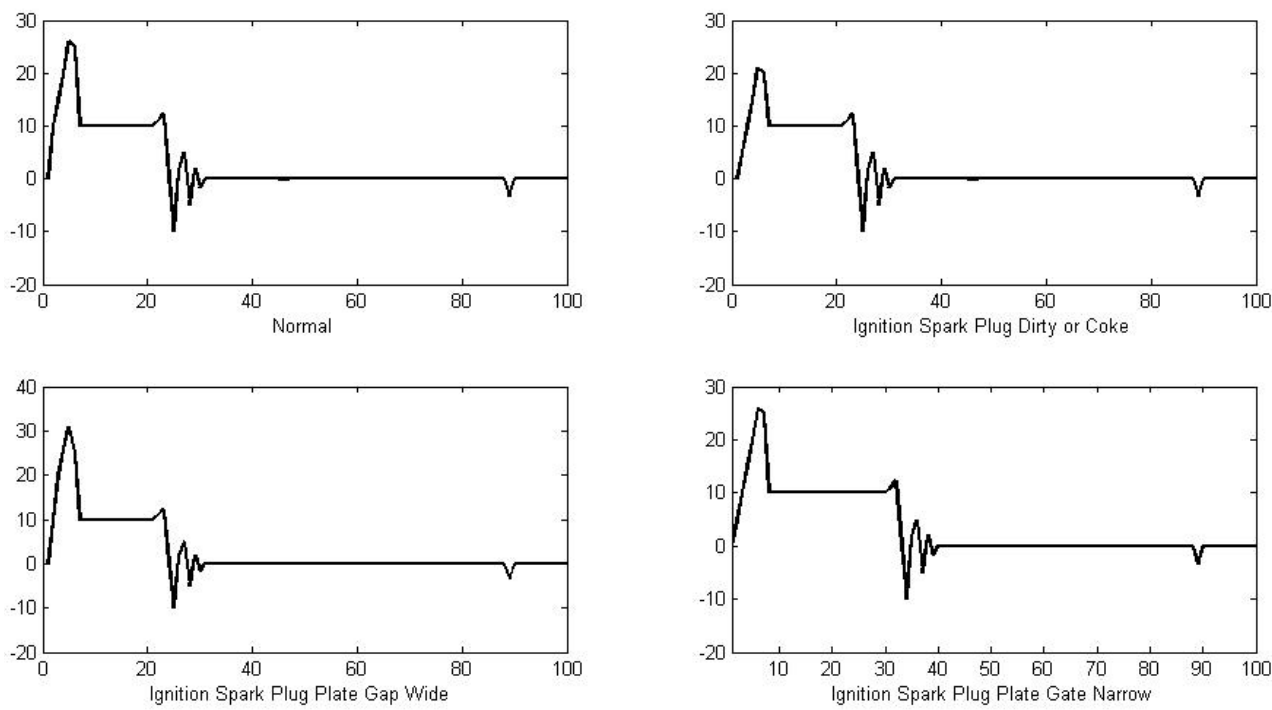

Fig. (5). Ignition system circuit faults simulation image.

Matlab was used to simulate ignition mathematical model and the system faults such as ignition exciter capacitor plates gap wide, ignition exciter capacitor plates gap narrow, ignition spark plug dirty or coked and so on. Each fault would conduct multiple simulations. In this way the ignition system theory database can be built with the simulation results. Ignition system circuit faults simulation image was shown in Fig. (5). Comparing to a standard ignition waveform, the ignition spark plug dirty or coked fault shows the combustion area ignition waveform downwardly. If the ignition exciter capacitor plates gap was too large or the secondary circuit was open, the ignition waveform shows the breakdown voltage is too high, and the spark line is steeper. Larger the

spark gap is, the desired breakdown voltage is higher, and the discharge process is not smoothly. If the ignition spark plug gap was too narrow, the ignition waveform breakdown voltage and spark lines are too low, and the spark line becomes long. In this case, the breakdown voltage will be low, while the spark discharge time will be longer.

\section{DESIGN OF IGNITION EXPERIMENTAL SYSTEM}

Aero-engine ignition system includes ignition power, ignition exciter, ignition lead and ignition spark plug, as shown in Fig. (6) [3]. 


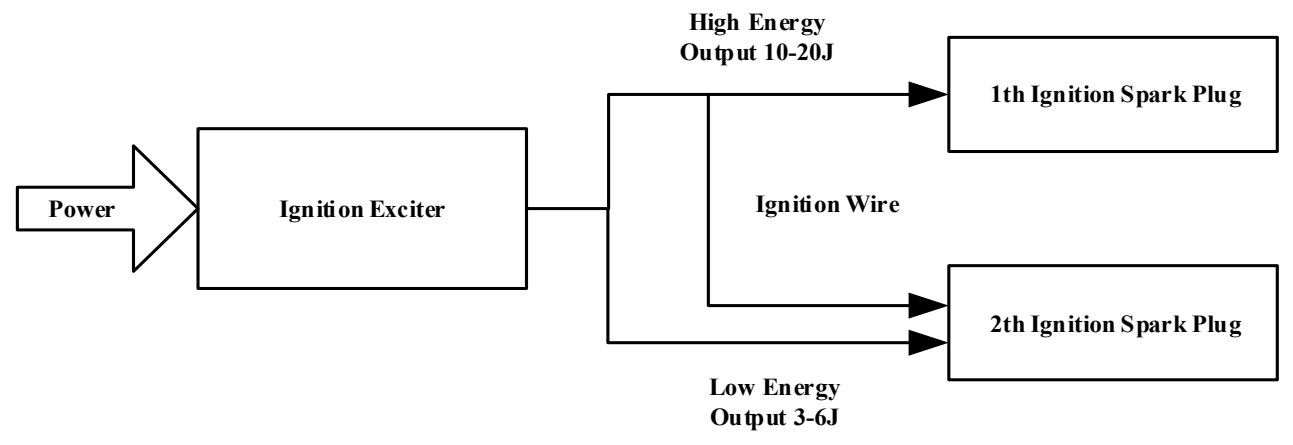

Fig. (6). Ignition system structure.

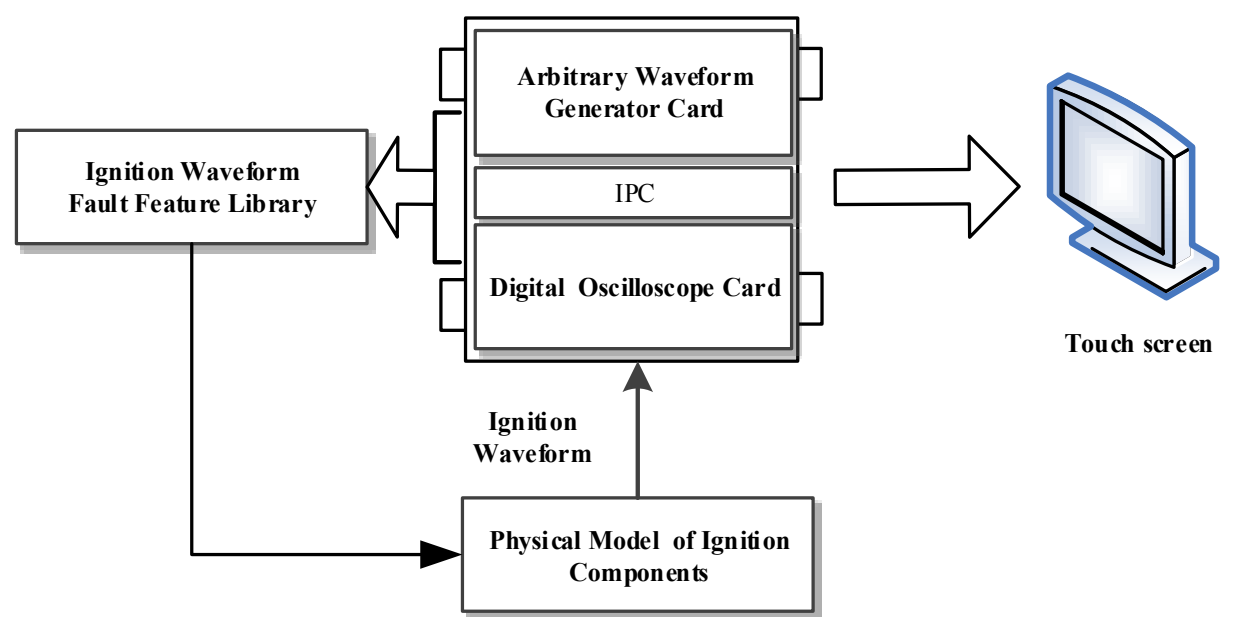

Fig. (7). Ignition faults experimental system platform based on LabVIEW.

Aero-engine ignition experimental system was built with physical model composed of the ignition exciter system, ignition leads and ignition spark plug. The power was $115 \mathrm{~V} / 400 \mathrm{HZ}$ AC. Embedded system was used to simulate ignition work process, use multiple ignition experiments and artificial to achieve ignition spark plug coked, ignition coil faults, ignition exciters and ignition spark plug component faults, use a portable industrial control computer to establish faults waveform database and deal with fault waveform. In addition, high-speed data acquisition card was used to work in the testing stage ignition system ignition waveform acquisition. In this way the ignition system experimental database can be built with the ignition experimental system. The real ignition waveform would be compared with the database waveform to determine the ignition system faults type, and the comparison result would be displayed on the display terminal. Ignition faults experimental system platform based on LabVIEW was shown in Fig. (7) [4, 5]. And the typical ignition energy waveform acquired from ignition experimental system is shown in Fig. (8).

\section{TYPICAL IGNITION SYSTEM FAULTS WAVE- FORM PRETREATMENT}

\subsection{Typical Ignition Waveform Analysis}

Aero-engine ignition standard waveform is shown in Fig. (9). If the basic feature of the measured ignition wave- form is different from the standard ignition waveform significantly, it can be determined that there exits faults of the ignition system. In order to facilitate the analysis, the ignition waveform for one cycle is always be divided into four parts: ignition area, combustion area, oscillation area, and mixing area.

Ignition area: Normal variation of the ignition area is that once the circuit abruptly cut off, the ignition coil primary winding current in vain decreased, the magnetic field generated by rapid decay, and the high voltage that can break down the ignition spark plug electrode gap is induced in the secondary winding. After the electrode gap was broken down, the secondary ignition voltage decreases. The voltage waveform showed a sharp rise and a sharp decline ignition lead in the near-vertical. Breakdown voltage is generally up to $22 \sim 26 \mathrm{KV}$.

Combustion area: Normal variation of the combustion area is that the ignition spark plug gap was broken down resulting in the combustible gas particles ionize between the ignition spark plug gap, and caused arc discharge. Secondary ignition voltage will be decreased, and maintain a constant voltage that can fit for the ignition spark plug electrode discharge requirements. So that the mixed gas within the cylinder to burn rapidly. The voltage waveform showed a slight fluctuations and slow decline over time ignition lead. The voltage in this stage is about a quarter of Up. 

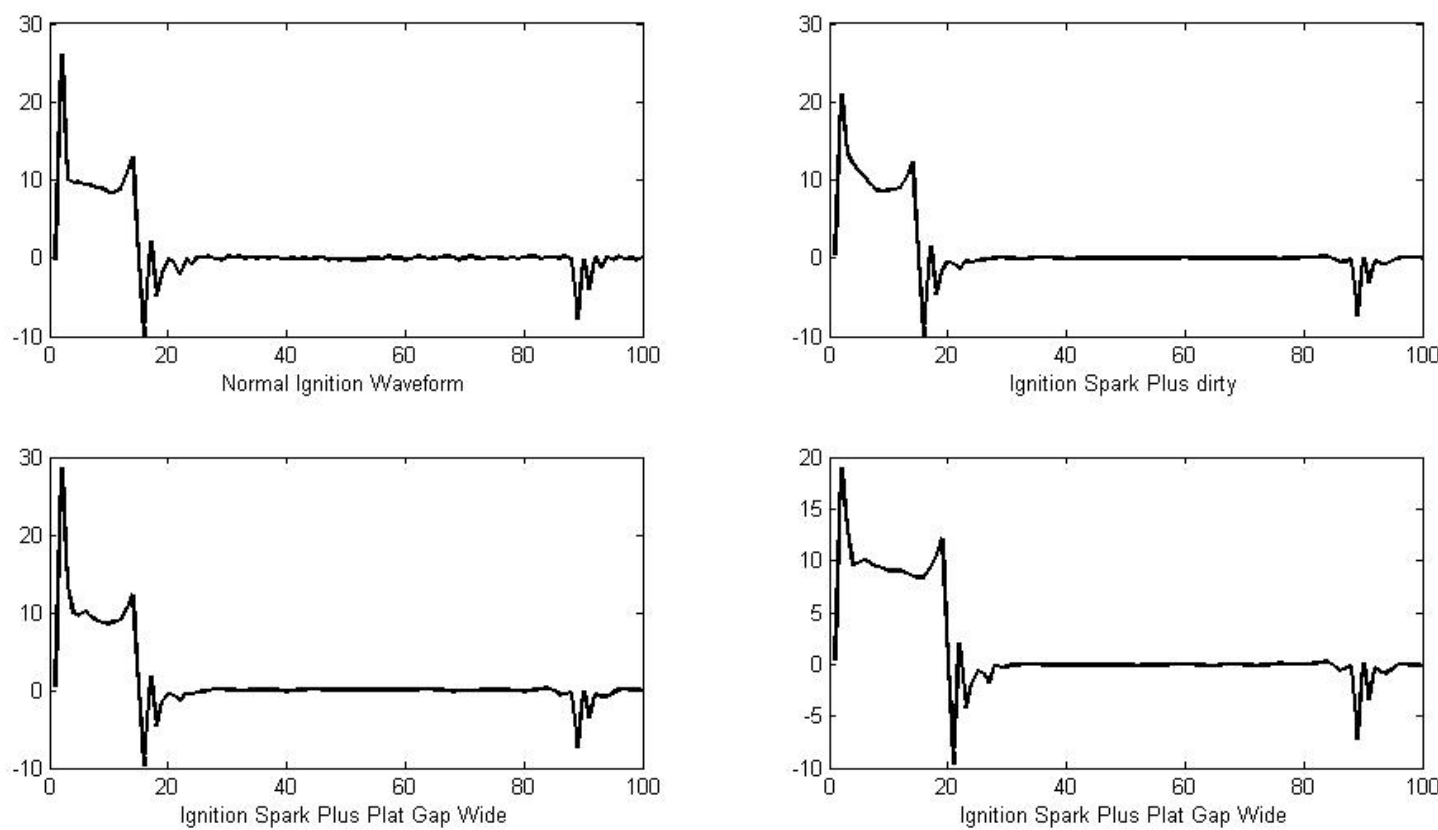

Fig. (8). Ignition energy waveform acquired from ignition experimental system.

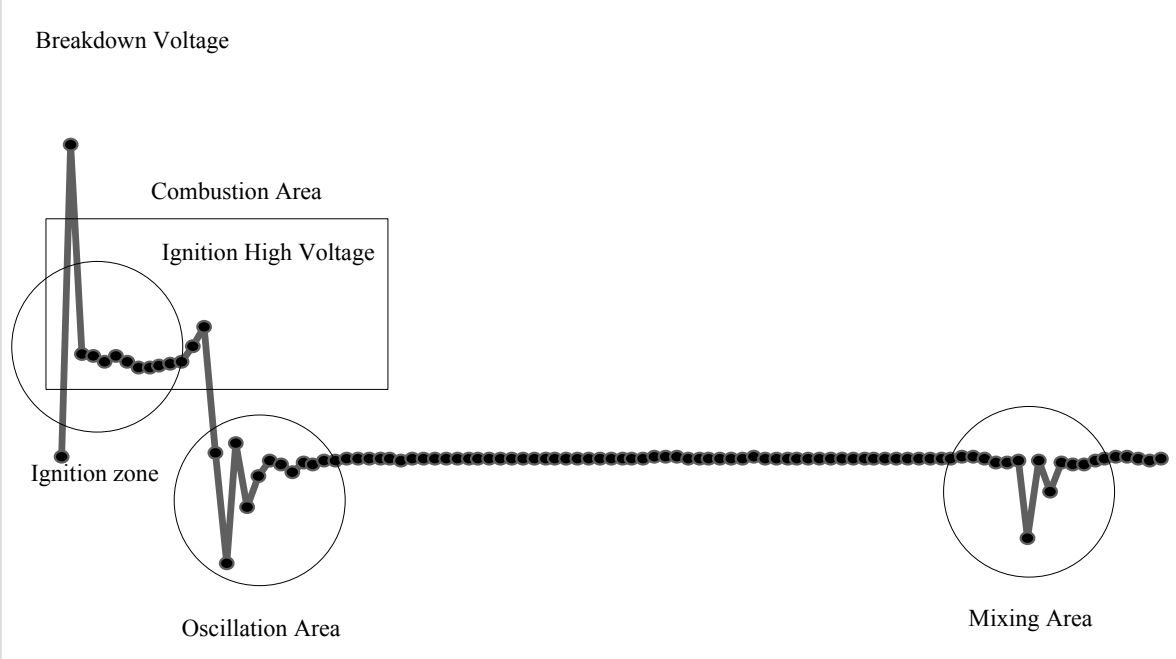

Fig. (9). Standard electronic ignition waveform.

Oscillation area: Normal variation of the oscillation area is that the energy in the ignition coil cannot be maintained for the spark discharge in the end of the ignition electrically nozzle discharge, and the residual energy exhausted in the form of a damped oscillation. There appears a larger visual oscillation pulse low-frequency oscillation region of the voltage waveform.

Mixing area: Normal variation of the oscillation area is that the induced voltage that has an opposite voltage polarity will be induced in the secondary circuit after the circuit is closed again. The performance of the voltage waveform is a rapid decline vertical line, and with a gradual increase of the primary current, the secondary induced voltage is also a corresponding increase, and then gradually oscillation rising transition to a horizontal line [6].

\subsection{Selection of the Characteristic Parameters}

In order to diagnose ignition system faults, the characteristic parameters must be chosen at first. Characteristic parameters means typical representative and can be used to describe the nature of the state system, reflects the common faults phenomenon and so on. Selected characteristic parameters shall conform to the following principles: good sensitivity, single value, stability, informational, convenience and economy. The ignition system should meet two requirements: produce enough voltage to breakdown ignition spark plug gap and enough spark energy. We generally choose the primary circuit voltage $(\mathrm{V})$, the voltage drop $(\mathrm{V})$ of the secondary circuit, the ignition hypertension $(\mathrm{kV})$, the breakdown 


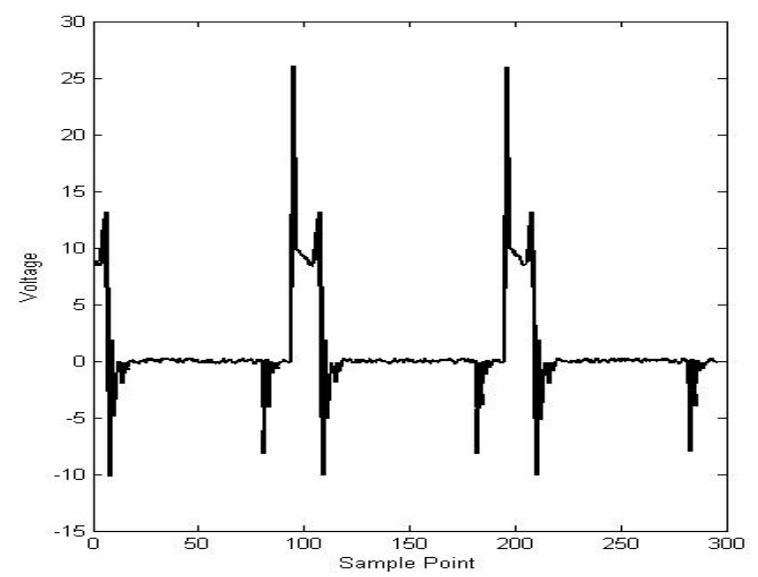

Fig. (10). Ignition signal split before and after comparison chart.

voltage of the secondary circuit $(\mathrm{kV})$, and the like parameters as ignition system characteristic parameters. In this paper, for experimental convenience, ignition high voltage and circuit breakdown voltage was used as the main characteristic parameters for both of them have connections with ignition spark plug gap, the mixture concentration, cylinder pressure, air flow changes and the technical condition of the various components of the ignition system and so on. The abnormal of the ignition voltage would cause engine power loose, poor economy, poor acceleration and other faults.

\subsection{Waveform Signal Splitting Procedures}

If there encounter a situation of continuous ignition, the ignition waveform can be acquired $2 \sim 7$ cycles. So signal acquisition program can obtain $2 \sim 7$ cycles of an ignition signal by setting the sampling points and the sampling frequency must be designed. Signal split procedures would follow $2 \sim 7$ cycles of the ignition signal in the array element circulating the judgment for determine which element is the position of the starting point of the ignition signal. As the waveform data points of a single cycle ignition roughly certain, the starting point of the entire array to obtain a single ignition waveform can be used to split the entire ignition waveform, so that the waveform data can be matched with the typical faults feature library. Ignition signal split before and after comparison waveform was shown in Fig. (10).

\section{WAVEFORM IMAGE MATCHING ALGORITHM}

The theory of waveform image matching is applied by matching waveform image diagnosed with that in the ignition waveform faults database to find the closest faults waveform image to confirm faults type generated corresponding to ignition fault waveform, as to achieve faults diagnosis purposes by the ignition voltage waveform [7-10].

In practical application, previously store several typical faults waveforms sample $\mathrm{F}_{T j}(\mathrm{t})(\mathrm{j}=1,2, \cdots, \mathrm{n} ; 0<\mathrm{t}<\mathrm{T})$, measured ignition waveform $\mathrm{F}_{R i}(\mathrm{t})$ as the test sample, then integral:

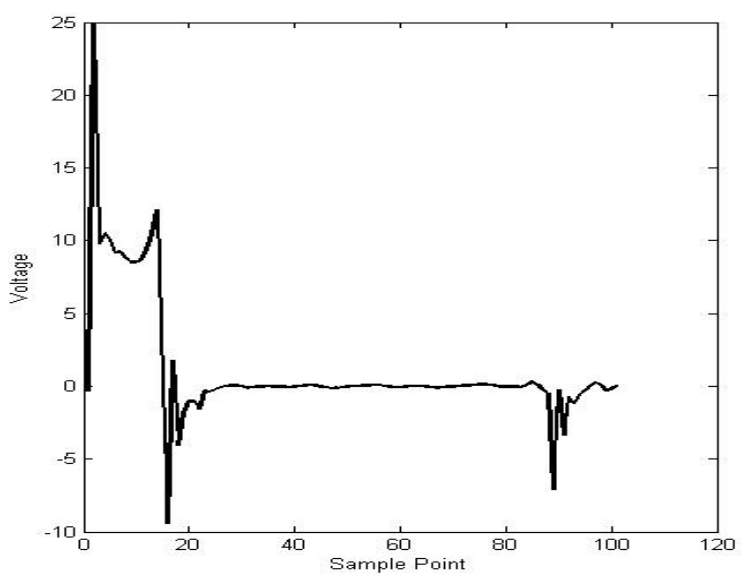

$\frac{1}{T} \int_{0}^{T}\left[F_{R i}(t)-F_{T j}(t)\right]^{2} d t=G(i, j)$

Indicate the mean square error of $\mathrm{F}_{R i}(\mathrm{t})$ and $\mathrm{F}_{T j}(\mathrm{t})$.

When $\mathrm{G}(i, j)$ is minimum, it indicates $\mathrm{F}_{R i}(\mathrm{t})$ is close to $\mathrm{F}_{T j}(\mathrm{t})$ in the minimum mean square error criterion. When $\mathrm{G}$ $(i, j)$ is closer to zero, $\mathrm{F}_{R i}(\mathrm{t})$ and $\mathrm{F}_{T j}(\mathrm{t})$ are more matching.

Expand Eq. (2):

$G(i, j)=\frac{1}{T}\left[\int_{0}^{T} F_{R i}(t) d t-2 \int_{0}^{T} F_{R i}(t) F_{T j}(t) d t+\int_{0}^{T} F_{T j}(t) d t\right]$

The first integral term of Eq. (3) indicates the energy of the test sample. It is the same for all the typical faults waveform samples. The purpose to identify and match the measured ignition waveform is to find the typical faults waveform samples $\mathrm{F}_{T j}(\mathrm{t})$ when $\mathrm{G}(i, j)$ is minimum. The value of $\mathrm{G}(i, j)$ is not cared about, therefore, the first integral term can be omitted. Eq. (3) becomes

$H(i, j)=\frac{2}{T} \int_{0}^{T} F_{R i}(t) F_{T j}(t) d t-\frac{1}{T} \int_{0}^{T} F_{T j}(t) d t$

Thus, the question is to find $\mathrm{F}_{T j}(\mathrm{t})$ when $\mathrm{H}(i, j)$ is maximum in the minimum mean square error criterion. The second integral term of Eq. (4) represents the energy of typical faults waveform samples, because the stored of typical faults waveform samples are different, this item can't be omitted. However, each typical faults waveform energy can be calculated, when storing typical faults waveform samples, finally the energy of typical faults waveform samples and the waveform samples is stored together. When it need to calculate the different test samples, it can directly call its energy value.

The process of calculation and comparison in the paper requires computer language programming to achieve. It should be noted that in each digital waveform matching process the precondition is to make the starting position and the end position same with that of the template waveforms after waveform vectorization, otherwise there will be deviation in 
Table 1. Ignition waveform matching value $G(i, j)$.

\begin{tabular}{|c|c|c|}
\hline Measured Waveform & Waveform in Faults Database & Matching Value $\boldsymbol{G}(\boldsymbol{i}, \boldsymbol{j})$ \\
\hline \hline Normal & Normal & 0.008735 \\
\hline Normal & Ignition exciter capacitor plates gap wide & 0.347500 \\
\hline Normal & Ignition exciter capacitor plates gap narrow & 11.352100 \\
\hline Normal\& Noise & Normal & 0.081785 \\
\hline Normal\& Noise & Ignition spark plug is dirty or coked & 0.309107 \\
\hline Ignition spark plug is dirty or coked & Ignition exciter capacitor plates gap wide & 0.700792 \\
\hline Ignition spark plug is dirty or coked & Ignition exciter capacitor plates gap narrow & 11.012300 \\
\hline Ignition exciter capacitor plates gap narrow & Ignition exciter capacitor plates gap narrow & 0.008966 \\
\hline
\end{tabular}

matching and recognition. In the process of comparison and matching it is impossible to match all the characteristics, because the number of feature points and the characteristics of the selected waveform must have differences. It is impossible to make $\mathrm{G}(i, j)$ to be absolute zero.

\section{IGNITION SYSTEM FAULTS DIAGNOSTICS AND RESULT ANALYSIS}

A field experiment was made in AMECO in which the ignition exciter produced by unison was used which were commonly seen in CFM56. The high voltage detector was adopted to convert the high voltage signal to a digital signal. Then the digital signal can be acquired by our ignition diagnosis system.

At first, the characteristic parameters must be chosen. The ignition waveform characteristic parameters are high voltage and breakdown voltage which are related to the ignition component technology and the situation of the characteristic parameters can affect the ignition performance in some extent. The breakdown voltage can be obtained by separate the data, dalta, attribute from the waveform data and array the waveform data from maximum value to the minimum value. The ignition high voltage can be obtained by extracting the fifth to 55 ignition waveform data and array the waveform data from maximum value to the minimum value.

Then the waveform matching procedure was sequentially compare the measured ignition waveform with the fault characteristic waveform in the database which acquired from the model and experimental system. And determine a corresponding ignition faults types by compare the threshold value $\mathrm{G}(i, j)$ calculated by waveform matching algorithm.

The specific steps are: 1) Comparing the measured ignition waveform with the fault characteristic waveform in faults database. If the value is in the threshold value, it means the normal waveform, unless is faulty waveform. Fault light is lit. 2) Faults waveform, then in turn be matched with other typical fault waveform in signature fault database. If a fault waveform within the threshold range, it is determined for the type of fault. 3) If the waveform we got cannot match with all the signature ignition waveform in the database, the judgment would be shown as unknown fault and the system would prompts you whether to save an unknown faults waveform.

The real ignition waveform datum were processed to obtain the matching of the various waveforms of the value of $\mathrm{G}(i, j)$, and to set the threshold value, such as shown in Table 1. From the Table 1 we can see matching value between the measured waveform and the waveform in faults database is less than 0.01 . So 0.01 is chosen to be the detection threshold. With the steps above, the ignition system faults can be decided by the matching value.

At last, the intelligent diagnosis software based on LabVIEW can be used to detect the aero-engine ignition system fault types conveniently. Fig. (11) is a normal ignition signal according to the diagnostic result while Fig. (12) is a coked ignition signal which was shown in the touch screen. The analysis result shows the ignition system healthy status and faults type. A lot of numerical tests show that our new methods are feasible and satisfactory.

\section{CONCLUSION}

Aero-engine ignition system, which includes ignition power, ignition exciter, ignition lead and ignition spark plug, is the core of the engine. Whether the engine can run safely and efficiently or not depends on the rationality and reliability of ignition system. This paper presents an aero-engine ignition system faults diagnosis system which composed of arbitrary wave form generator card, digital oscilloscope card. Industrial control computer in hardware and physical model of ignition system, diagnosis program in software that can diagnose the ignition exciter capacitor plates gap wide, ignition exciter capacitor plates gap narrow, and ignition spark plug is dirty or coked faults.

The ignition system mathematical model was established which composed of ignition exciters, ignition leads and ignition spark plug to analysis the resistance, capacitance and inductance parameter changes of the ignition exciters, 


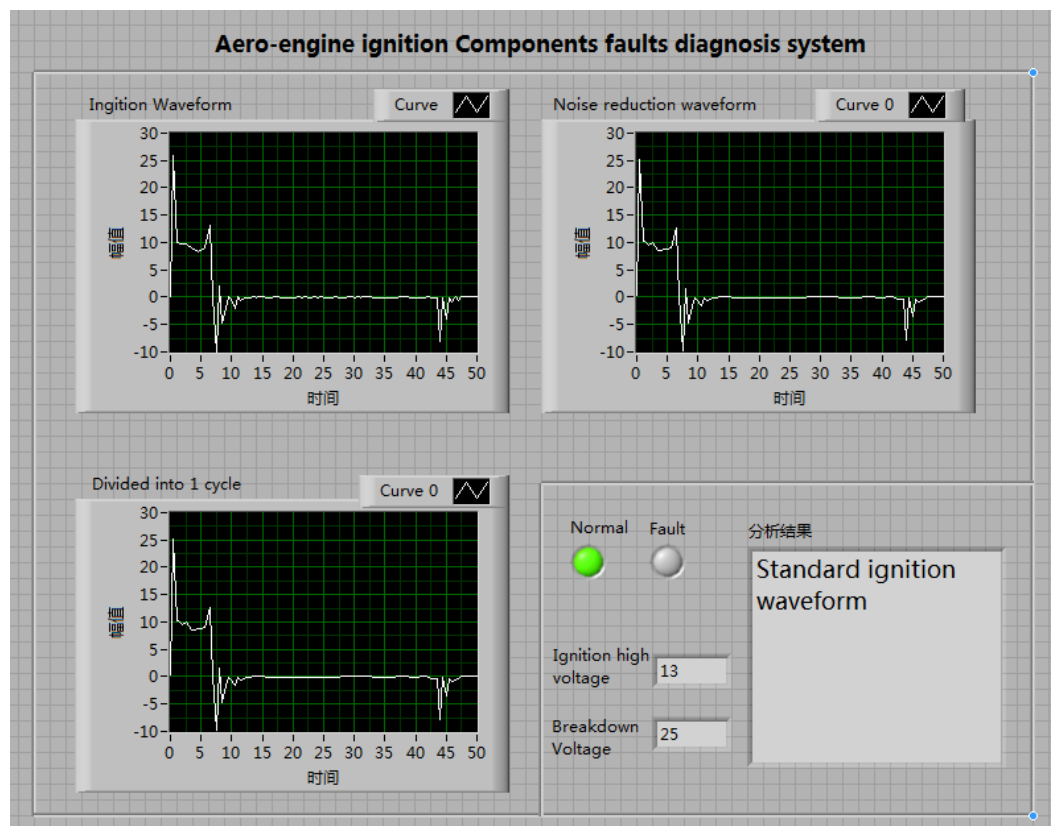

Fig. (11). Normal ignition signal.

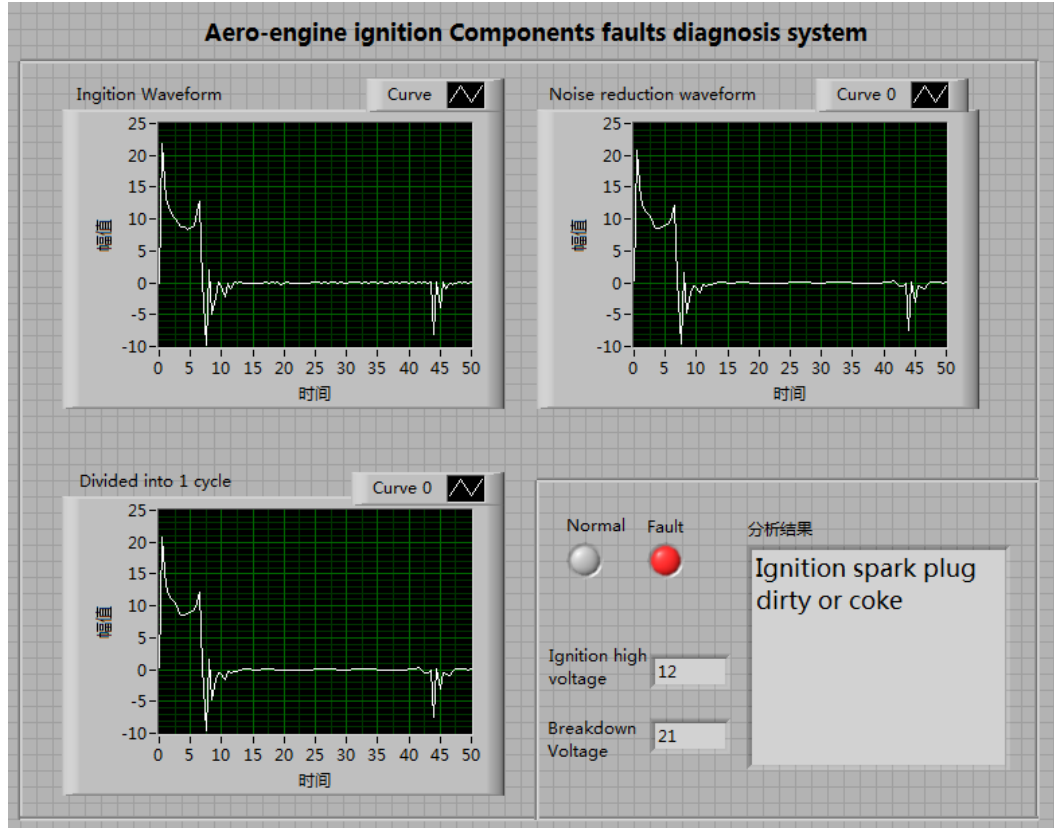

Fig. (12). Coked ignition signal.

ignition leads and ignition spark plug under faulty conditions. With the starter ignition experiment system to simulate ignition component faults, acquire ignition waveform and establish ignition component faults database. Research on the ignition waveform matching and acceleration algorithms, compared the ignition waveforms with the ignition component faults database waveform data to achieve ignition component faults diagnosis. With this method, the intelligent diagnosis based on LabVIEW can detect the aero-engine ignition system fault types conveniently. Furthermore, the proposed solution may also be used in the other part of the aero-engine such as gas system, bleed air system and so on.
For the inevitably generated in the process of signal transmission delay, and the electromagnetic interference in the transmission process, there may be resulting in a certain degree of error. So how to avoid the influencing factors to enhance the measurement accuracy will be our future research directions.

\section{CONFLICT OF INTEREST}

The author confirms that this article content has no conflict of interest. 


\section{ACKNOWLEDGEMENTS}

This work is supported by National Natural Science Foundation of China (Grant No. \#U1233201); Tianjin Science and Technology Support Key Project (Grant No. \#11ZCKFGX04000); Fundamental Research Project of the Central Universities (Grant No. \#ZXH2012B002 \& No. \#3122013P005\& No. \#3122013D006).

\section{REFERENCES}

[1] F. R. F. Ramsay and W. Nethercot, "Engine ignition faults, and a new method of diagnosis and location during running," Journal of the Institution of Electrical Engineers-Part II: Power Engineering, vol. 93, no. 36, pp. 629-635, 1946.

[2] W. E. Berkey, "Electrical Measurements on Aircraft-Engine Ignition Circuits," American Institute of Electrical Engineers, Transactions, vol. 65, no. 2, pp. 49-53, 1946.

[3] G.H. Abd Alla, "Computer simulation of a four stroke spark ignition engine," Energy conversion and Management, vol. 43, no. 8, pp. 1043-1061, 2002.

[4] R. K. Thulasiram and P. Thulasiraman, "Performance evaluation of a multithreaded fast Fourier transform algorithm for derivative pricing," The Journal of Supercomputing, vol. 26, no. 1, pp. 43-58, 2003.

[5] B. Wu, L. Lin, and C. Cai, "The diagnosis system of mechanical fault based on LabVIEW platform and its application", In: $3^{\text {rd }}$ International Conference on Intelligent Information Technology Application, 2009, pp. 322-325.

[6] S. Barua, R.K. Thulasiram, and P. Thulasiraman, "High performance computing for a financial application using Fast Fourier Transform," Euro-Par 2005 Parallel Processing vol. 24, pp. 12461253, 2005.

[7] D. L. Hung, D.M. Chmiel, and L.E. Markle, "Application of an imaging-based diagnostic technique to quantify the fuel spray variations in a direct-injection spark-ignition engine," SAE Technical Paper, No. 2003-01-0062, 2003.

[8] G. Markovich, M. Skolnick, and M. Core, "A new methodology for isolating and diagnosing inconsistencies in image matching as applied to the analysis of 2-d electrophoretic gels," Applications of Computer Vision, vol. 73, pp. 197-204. 1992.

[9] L .Tian, X. Li and C. Liu, "Design of fault diagnosis system for aircraft engine ignition component," Journal of Civil Aviation University of China, vol. 31, no. 4, pp. 6-9, 2013.

[10] X. Shi, G. Ren, J. Li, "Fault diagnosis method research of aircraft ignition system based on waveform image matching," Procedia Engineering, vol.15, pp. 2527-2532. 2011.

Received: November 26, 2014

Revised: January 09, 2015

Accepted: January 22, 2015

(C) Meng et al.; Licensee Bentham Open.

This is an open access article licensed under the terms of the Creative Commons Attribution Non-Commercial License (http://creativecommons.org/licenses/by-nc/3.0/) which permits unrestricted, non-commercial use, distribution and reproduction in any medium, provided the work is properly cited. 